\title{
miRNA-31 over-expression improve synovial cells apoptosis induced by RA
}

\author{
Luo C, Liang JS, Gong J, Zhang HL, Feng ZJ, Yang HT, Zhang HB, Kong QH \\ Geriatric Department of Orthopedics, the Second Hospital of Tangshan City, Hebei province, PR China. \\ liangjunsheng0122@163.com
}

\section{ABSTRACT}

OBJECTIVE: The aim of this study was to evaluate the effects and mechanism of miRNA-31 in synovial cells apoptosis induced by RA.

METHODS: The miRNA-31 gene expressions were extracted from synovial tissues of normal and RA patients by RT-PCR and H \& E staining. The synovial cells of RA patients were isolated and randomly divided into Control, Blank and miRNA groups. The cell apoptosis of difference groups were measured by flow cytometry; the TNF- $\alpha$ and IL- $1 \beta$ concentrations of difference groups were measured by Elisa assay; TLR4 and NF-KB proteins expressions were measured by WB assay and the correlation between TLR4 and miRNA-31 were evaluated by double luciferase target experiment.

RESULTS: The miRNA-31 gene expression was significantly suppressed in RA tissues $(p<0.001)$; Compared with control group, the cell apoptosis rate of miRNA group was significantly suppressed $(p<0.001)$; TNF- $\alpha$ and IL-1 $\beta$ concentrations were significantly down-regulation in culture fluid ( $p<0.001$, respectively) and TLR4 and NF-KB proteins expressions were significantly depressed ( $p<0.001$, respectively) in miRNA group. By double luciferase target experiment, the TLR4 was a target gene of miRNA-31.

CONCLUSION: miRNA-31 is a key role in synovial cells apoptosis induced by RA (Fig. 7, Ref. 23). Text in PDF wWw.elis.sk.

KEY WORDS: miRNA-31, cell apoptosis, RA; TLR4, NF-KB.

\section{Introduction}

Rheumatoid arthritis (RA) is a chronic inflammatory, symmetrical and systematic autoimmune disease (1). The etiology and mechanism of RA has been unclear and there is no cure for it at now (2), non-steroidal anti-inflammatory drugs (NSAIDs) are the main methods for clinical treatment of RA (3). There were some adverse reactions and severe gastrointestinal reactions in process of non-steroidal anti-inflammatory drugs treatment (4). MiRNA is a kind of non encoding single stranded RNA molecules encoding the endogenous gene length of about 22 nucleotides, highly conserved in evolution, the suppression of mRNA expression by inhibiting the target rent target mRNA translation process or influence the stability of mRNA, and a variety of physiological processes in vivo play an important role in the pathogenesis of miRNA and many diseases are closely related (5). There had been reports that a variety of miRNA were abnormal in RA patients (610). miRNA-31 was an important role in cell apoptosis $(11,12)$.

Geriatric Department of Orthopedics, the Second Hospital of Tangshan City, Hebei province, PR China

Address for correspondence: JS Liang, Geriatric Department of Orthopedics, the Second Hospital of Tangshan City, Hebei province, PR China, 063000
However, It has been unclear that the effects and mechanism of miRNA-31 in RA development.

\section{Materials and methods}

\section{Clinical sample}

Synovial tissues were taken from joint replacement patients which were joint injury or RA from the Second Hospital of Tangshan City. The synovial tissues were stored at $-80^{\circ} \mathrm{C}$ until measured the miRNA-31 gene expression by RT-PCR assay and fixed in the $10 \%$ polyoxymethylene until H\&E staining.

\section{RT-PCR assay}

The total RNA were extracted from normal and RA synovial tissues by Supplier Agreement of Trizol (Invitrogen, USA); Taking RNA to measure pure by ultraviolet spectrophotometer, the purity is $1.8-2.1$ in conformity with the requirements to continue the next step. cDNA reverse transcriptase synthesis by supplier aggrement of miRNA reverse transcriptase synthesis kit, the miRNA-31 gene expression was measured by Real-timePCR instructions (Tanara, Japan). The miRNA-31 gene primer sequence (Nanjing Kingsy biological technology company, China) as following: miRNA-31: F: 5'-GGAGAGGAGGCAAGATGCTG-3'; R: 5'-GGAAAGATGGCAATATGTTG-3'; U6: F: 5'-TCGCTTCGGCAGCACATA-3'; R: 5'-GGCCATGCTAATCTTCTCTG-3'. 


\section{5-360}

Each sample was set up with 3 complex holes for quantitative detection. The reaction takes U6 as the internal reference. The CT value of each hole was recorded, the average value of each hole was taken as the result, and the results were analyzed by $2^{-\triangle \Delta C T}$ method.

\section{$H \&$ E staining}

The synovial tissues were fixed in the $10 \%$ polyoxymethylene for $24 \mathrm{~h}$, Paraffin embedded, made into $5 \mu \mathrm{m}$ slices, the sections were $\mathrm{H} \& \mathrm{E}$ staining, observation pathological changes under optical microscope.

\section{$R A$ separation and culture of synovial cells}

The synovial tissues of the knee joint were removed in a sterile environment, washing by PBS, the synovial tissues were cut, added $2 \mathrm{ml}$ DMEM culture fluid and $2 \mathrm{ml}$ I type collagenase (2.5 $\mathrm{mg} / \mathrm{ml})$ to culture in incubator $\left(37^{\circ} \mathrm{C}, 5 \% \mathrm{CO}_{2}\right)$ for $4-6 \mathrm{~h}$, filtering, centrifugal, discarding the supernatant. Adding DMEM culture solution to resuspension cell, the cells as $1 \times 10^{6}$ cells $/ \mathrm{ml}$ were inoculated in the cell culture bottle. The cells were cultured in the incubator $\left(37^{\circ} \mathrm{C}, 5 \% \mathrm{CO}_{2}\right)$.

\section{Grouping and treatment}

The synovial cells were randomly divided into control group which were treated with normal treatment; Blank group which were transferred with empty vector and miRNA group which were transferred with miRNA-31. The synovial cells were taken and inoculation in 6-hole culture dish, there were $1 \times 10^{6}$ cells $/ \mathrm{ml}$ in every holes. When the cell density was $80-90 \%$, the cells of Blank and miRNA groups were transferred with Lipofectamine ${ }^{\mathrm{TM}}$ 2000 (Sigma, USA) or miRNA-31 (Sigma, USA) following by Supplier Agreement.

\section{MTT assay}

After transfection for $72 \mathrm{~h}$, the logarithmic growth period synovial cells of difference groups were collected and washed by PBS, added $0.25 \%$ trypsin to digest, centrifugal, made as single cell suspension, regulation cell suspension as $1 \times 10^{6}$ cells $/ \mathrm{ml}$, Inoculated in the 96-hole plate, culture overnight, added $20 \mu \mathrm{l}$ MTT $(5 \mathrm{mg} / \mathrm{ml})$ and cultured at $37^{\circ} \mathrm{C}$ for $4 \mathrm{~h}$, removing the supernatant, added $100 \mu \mathrm{l}$ DMSO to every holes. After shocking for $10 \mathrm{~min}$, the absorbance value were measured at $570 \mathrm{~nm}$, and measured the cell proliferation.

\section{Cell apoptosis by flow cytometry}

After transfection for $48 \mathrm{~h}$, the cells of difference groups were collected and washed by PBS for 2 times. Adding $100 \mu 1$ Binding buffer to resuspension cells, after that, added $5 \mu 1$ Annexin $V$ and $1 \mu \mathrm{PI}$ to culture for $15 \mathrm{~min}$ in dark, added $400 \mu \mathrm{l}$ Binding buffer to measure the cell apoptosis by flow cytometry, using FlowJo 7.6 software to analysis apoptosis.

\section{TNF- $\alpha$ and IL-1 $\beta$ concentrations by Elisa assay}

After treatment for $48 \mathrm{~h}$, the culture fluid of difference groups were collected and centrifugal to collect supernatant. The TNF- $\alpha$ and IL-1 $\beta$ concentrations were measured by Elisa kits following by supplier agreement.

\section{The relative proteins expression by $W B$ assay}

The total protein was extracted by total protein extraction kit (NanJing KeyGen Biotech Co., Ltd., China), the total protein concentration was measured by BCA method (NanJing KeyGen Biotech Co., Ltd., China), the $20 \mu \mathrm{g}$ total protein was taken to electrophoretic separation by $10 \%$ SDS-PAGE, transferred the protein to PVDF member, adding the first antibodies (GAPDH 1:1000; TLR4 1:1000 and NF- $\kappa B$ 1:500) to culture overnight at 4 ${ }^{\circ} \mathrm{C}$, washing by PBS, added HRP marked second antibody $(1: 1000)$ to culture for $1 \mathrm{~h}$, adding enhanced chemiluminescence (ECL) to color, using Chemiluminescent imaging system (TANON 5200) to analysis the gray value by Imagel software.

\section{Double luciferase reporter gene experiment}

The TLR4-UTR sequence and its mutants containing the miRNA-31 binding site were inserted into the downstream of the luciferase reporter gene of the pmirGLO vector. The wild type and mutants obtained were named as TLR 4-WT and TLR4-Mul, constructed the plasmid, miRNA-Control and miRNA-31 were transfected into synovial cells; cultured at $48 \mathrm{~h}$ after transfection, using dual luciferase reporter gene assay kit for detection of luciferase activity in cells.

\section{Statistical analysis}

The relative data of this study were analysis by SPSS 22.0 software and shown as mean \pm SD (standard deviation); The difference was analysis by one way ANOVA with t-test, $p<0.05$ was shown the difference had statistical significance.

\section{Results}

miRNA-31 gene expression and pathology of difference tissues

Compared with normal synovial tissue, the miRNA -31 gene expression was significantly suppressed in RA synovial tissue ( $p$ $<0.001$ ) (Fig. 1). By H \& E staining, In NC rats, the pathology of synovial tissue had no changes. The synovial layer is composed

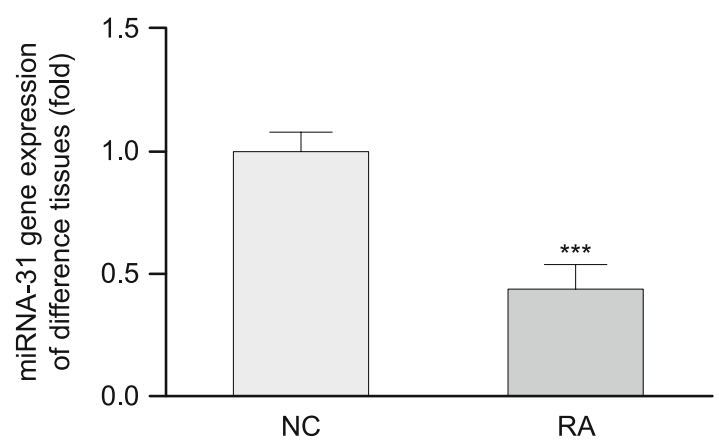

Fig. 1. The miRNA-31 gene expression in NC and RA synovial tissues by RT-PCR. *** $p<0.001$, compared with NC. 
NC

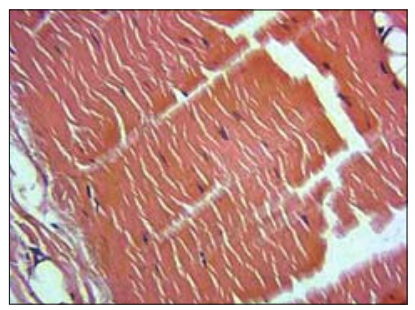

Fig. 2. The pathology of NC and RA synovial tissues by H\&E staining $(\times 200)$.

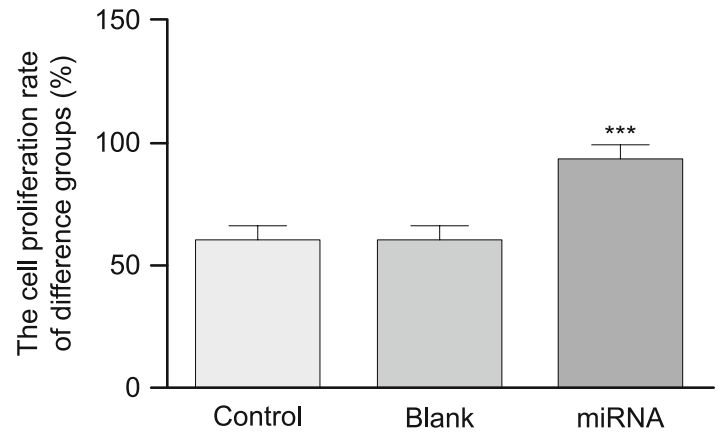

Fig. 3. The cell proliferation rate of difference groups by MTT assay. $* * * \mathbf{p}<\mathbf{0 . 0 0 1}$, compared with Control group.
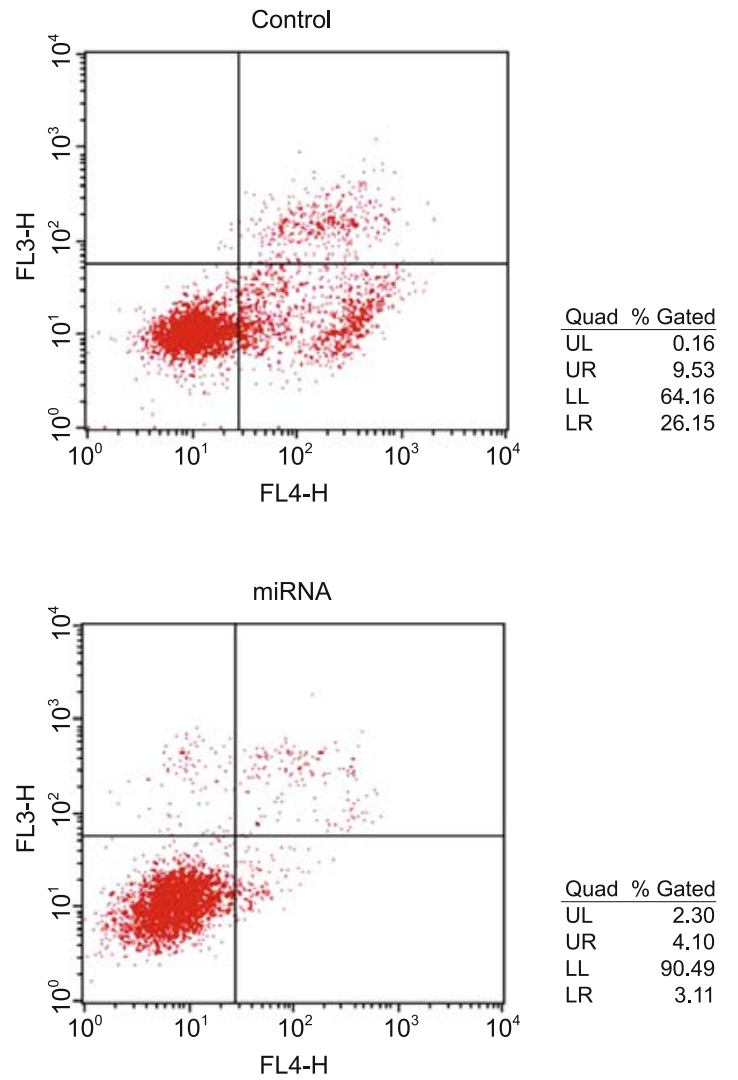

of the membrane cells and arranged in an orderly manner. The pathology of RA synovial tissues were the thickness of the matrix layer was obviously thickened, the structure of the collagen fibers in the subsynovial layer changed, and the inflammatory cells were mainly infiltrated by lymphocyte (Fig. 2). Depending on these results, we inferred that miRNA-31 knockdown might be the result which lead RA in RA patients. We wanted to verification miRNA-31 effects by following experiment.

\section{The cell proliferation and apoptosis of difference}

The cell proliferation rate of miRNA group was significantly up-regulation compared with that of Control group $(\mathrm{p}<0.001)$ (Fig. $3)$ and there were no significantly difference between Control and Blank groups ( $p>0.05)$ (Fig. 3). Meanwhile, The cell apoptosis rate of miRNA group was significantly suppressed compared with that of Control group ( $<$ 0.001) (Fig. 4); the cell apoptosis rate of Blank group was no significantly difference compared with Control group $(p>0.05)$ (Fig. 4). These results were shown that miRNA-31 overexpression had effects to improve synovial cell proliferation by suppressing cell apoptosis induced by RA.

\section{The relative inflammatory factors of difference groups}

To evaluate the relative inflammatory factors expression in difference groups, we measured the TNF- $\alpha$ and IL- $1 \beta$ concentrations
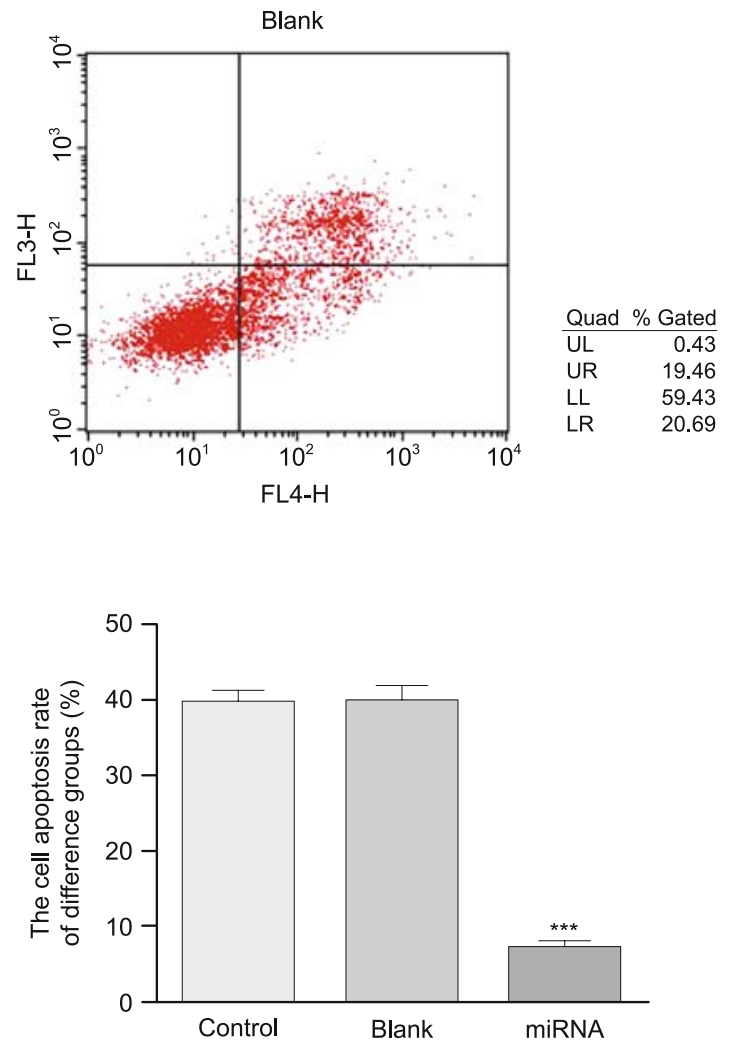

Fig. 4. The cell apoptosis rate of difference groups by flow cytometry. $* * * p<0.001$, compared with Control group. 

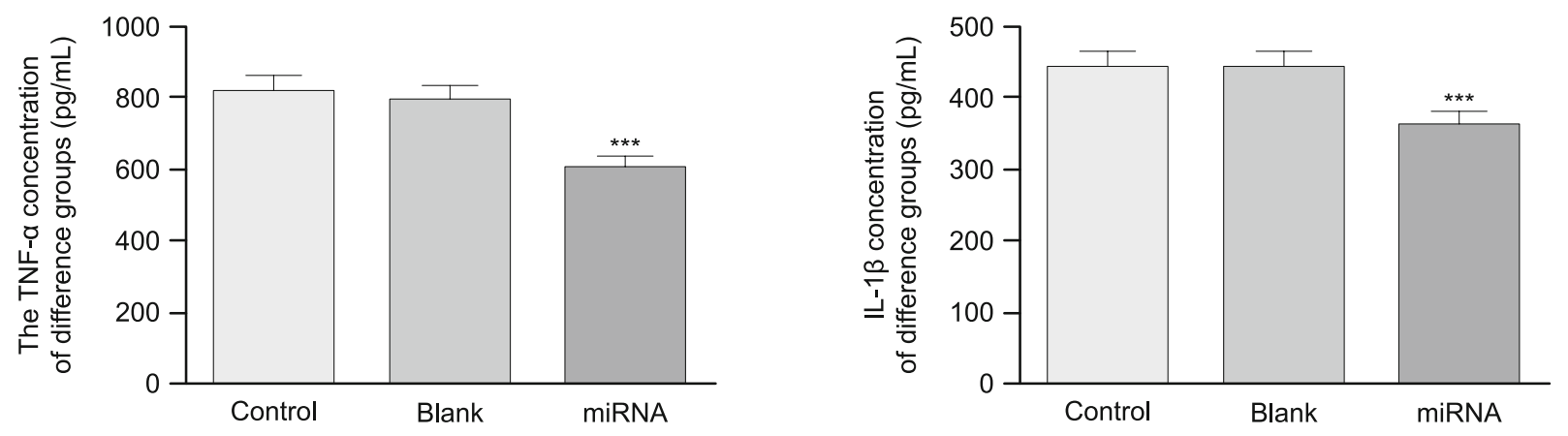

Fig. 5. The IL-1 $\beta$ and TNF- $\alpha$ concentrations of difference groups by Elisa assay. $* * * p<0.001$, compared with Control group.
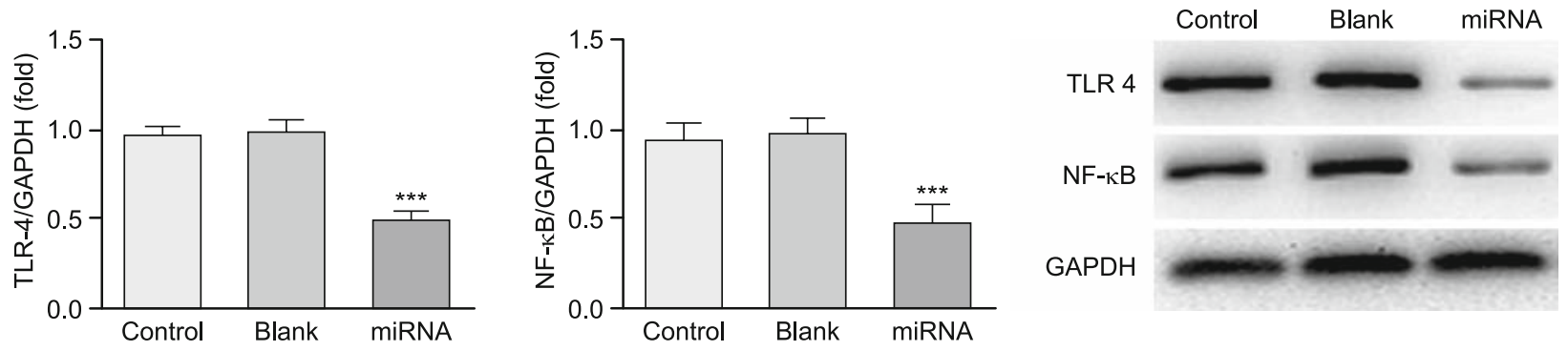

Fig. 6. The relative proteins expressions of difference groups by WB assay. $* * * p<0.001$, compared with Control group.

\begin{tabular}{|l|l|l|l|}
\hline Position 11-37 of TLRA4 3' UTR & $5^{\prime}$... AAACCUCCUG-AGGCAUUUCUUGCCC. . & 7mer-m8 \\
hsa-miR-31 & $3^{\prime} \quad$ GUCGAUACGGUCGU--AGAACGGA & \\
\hline
\end{tabular}

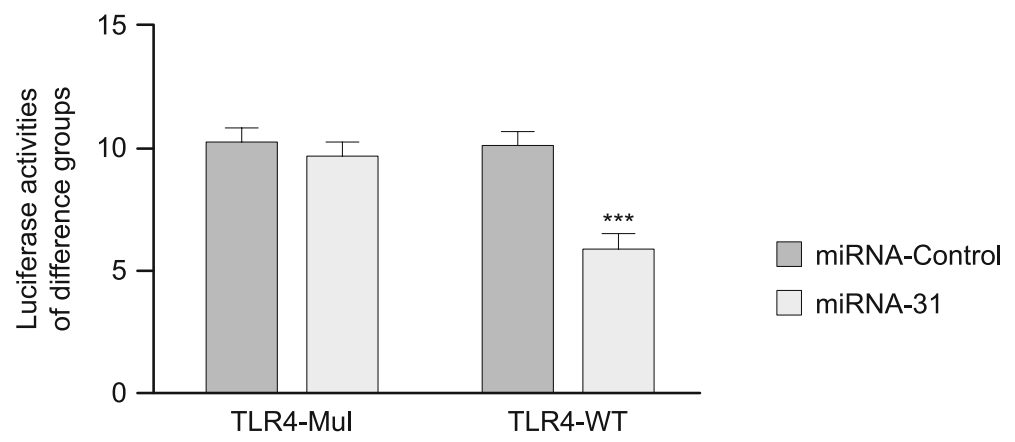

Fig. 7. Double luciferase target experiment. *** $\mathrm{p}<0.001$, compared with miRNA-Control.

of difference groups in culture fluid by Elisa assay. The results were shown that the TNF- $\alpha$ and IL- $1 \beta$ concentrations were significantly reduced with miRNA-31 over-expression in miRNA group $(\mathrm{p}<$ 0.001 , respectively). The relative data were shown in Figure 5.

The relative protein expression of difference groups by WB assay

By WB assay, we measured the relative proteins expression to explain the mechanism of miRNA-31 in RA treatment. The results were shown that TLR4 and NF- $\kappa$ B proteins expressions of
miRNA group were significantly depressed compared with those of Control group ( $p<0.001$, respectively) and there were no significantly differences between Control and Blank groups in TLR4 and $\mathrm{NF}-\kappa \mathrm{B}$ proteins expression in vitro study $(\mathrm{p}>0.05$, respectively). The relative data were shown in Figure 6.

\section{The correlation between miRNA-31 and TLR4}

To analysis the correlation between miRNA-31 and TLR4, we used double luciferase target experiment to verification the cor- 
relation between miRNA-31 and TLR4. The results were shown that the LUC activities of miRNA-Control and miRNA-31 were no significantly differences in TLR4-Mul, however, the miRNA-31 was significantly suppressed compared with miRNA-Control in TLR4-WT $(\mathrm{p}<0.001)$. Depending on those results, we inferred that TLR4 might be the target gene of miRNA-34. The relative data were shown in Figure 7.

\section{Discussion}

Rheumatoid arthritis (RA) is a multisystemic inflammatory autoimmune disease that mainly involves the surrounding joints. Rheumatoid arthritis is a serious threat to human health due to its high disability rate and organ involvement. At present, the effect of clinical treatment is also needed to improve. Therefore, it is necessary to explore the treatment of RA.

miRNA is encoded by the corresponding gene and is transcribed through a series of processing processes to form a mature small RNA molecule. Mature miRNA is retained in functional complexes, and plays an important regulatory role in gene expression by inhibiting the translation of mRNA or affecting the stability of mRNA by binding to target mRNA (13). MiRNA is a key part of the regulation of cytokine signaling pathway and rheumatoid arthritis (14-16). Therefore, we study the interaction of rheumatoid arthritis and miRNA and explore the downstream signal pathway, so as to provide a theoretical basis for the rational treatment and intervention of RA (17). In our present study, we firstly evaluated miRNA-31 gene expression and evaluated the pathology in normal and RA synovial tissues, the results were shown that miRNA-31 gene expression was down-regulation with RA pathology change. Depending on those results, we hypothesized that miRNA-31 over-expression may improve synovial cell injury induced by RA. In the vitro cell experiment, the results were shows that miRNA-31 overexpression enhanced synovial cell proliferation by suppressing cell apoptosis.

IL-1 $\beta$ and TNF- $\alpha$ are two important roles of inflammation in RA development (18-20). IL-1 $\beta$ and TNF- $\alpha$ high concentration leaded cell apoptosis $(21,22)$. TLR4 plays an important role in the body's immune defense. As a bridge between immune response and inflammatory response, TLR4 ligand can activate NF- $\mathrm{BB}$ transcription factor, and the expression of many inflammatory factors needs NF- $\kappa$ B participation (like as IL-1 $\beta$ and TNF- $\alpha$ ) (23). In present study, with miRNA-31 supplement, the RA synovial cell apoptosis was suppressed, meanwhile, the results also found that IL- $1 \beta$ and TNF- $\alpha$ concentrations were decreased via suppressing TLR4/NF- $\kappa B$ activation. Depending on those results, we inferred that TLR4 might be a target gene of miRNA-31. By double luciferase target experiment, the result confirmed TLR4 was a target gene of miRNA-31.

\section{Conclusion}

miRNA-31 was a potential therapeutic gene to RA.miRNA-31 over-expression had effects to improve synovial cell proliferation by suppress apoptosis and regulate IL- $1 \beta$ and TNF- $\alpha$ concentration via TLR4/NF- $\mathrm{BB}$ pathway.

\section{References}

1. Coiffier G, Bouvard B, Chopin F, Biver E, Funck-Brentano T, Garnero $\mathbf{P}$, Guggenbuhl P. Common bone turnover markers in rheumatoid arthritis and ankylosing spondylitis: a literature review Joint Bone Spine 2013; 80 (3): 250-257.

2. Walsh DA, McWilliams DF. Mechanisms, impact and management of pain in rheumatoid arthritis Nat Rev Rheumatol 2014; 10 (10): $581-592$.

3. Deane KD. Can rheumatoid arthritis be prevented? Best Pract Res Clin Rheumatol 2013; 27 (4): 467-485.

4. Ramiro S, Gaujoux-Viala C, Nam JL, Smolen JS, Buch M, Gossec L, van der Heijde D, Winthrop K, Landewé R. Safety of synthetic and biological DMARDs: a systematic literature review informing the 2013 update of the EULAR recommendations for management of rheumatoid arthritis Ann Rheum Dis 2014; 73 (3): 529-535.

5. Filipowicz W, Bhattacharyya SN, Sonenberg N. Mechanisms of posttranscriptional regulation by microRNAs: are the answers in sight Nat Rev Genet 2008; 9 (2): 102-114.

6. Wu YH, Liu W, Xue B, Zhang L, Liu XY, Liu B, Wang Y, Cai Y, Duan R. Upregulated Expression of microRNA-16 Correlates with Th17/ Treg Cell Imbalance in Patients with Rheumatoid Arthritis DNA Cell Biol 2016; 35 (12): 853-860.

7. Filková M, Aradi B, Senolt L, Ospelt C, Vettori S, Mann H, Filer A, Raza K, Buckley CD, Snow M, Vencovský J, Pavelka K, Michel BA, Gay RE, Gay S, Jüngel A. Association of circulating miR-223 and miR-16 with disease activity in patients with early rheumatoid arthritis Ann Rheum Dis 2014; 73 (10): 1898-904.

8. Xu WD, Lu MM, Pan HF, Ye DQ. Association of MicroRNA-146a with authoimmune disease Inflammation 2012; 35 (4): 1525-1529.

9. Yao R, Ma YL, Liang W, Li HH, Ma ZJ, Yu X, Liao YH. MicroRNA-155 modulates Treg and Th17 cells differentiation and Th17 cell function by targeting SOCS1 PLoS One 2012; 7 (10): e46082.

10. Stanczyk J, Ospelt C, Karouzakis E, Filer A, Raza K, Kolling C, Gay R, Buckley CD, Tak PP, Gay S, Kyburz D. Altered expression of microRNA-203 in rheumatoid arthritis synovial fibroblasts and its role in fibroblast activation. Arthritis Rheum 2011; 63 (2): 373-381.

11. Zhang J, Xu D, Li N, Li Y, He Y, Hu X, Lyu L, He L. Downregulation of microRNA-31 inhibits proliferation and induces apoptosis by targeting HIF1AN in human keloid Oncotarget 2017; 8 (43): $74623-74634$.

12. Nan X, Qin S, Yuan Z, Li Y, Zhang J, Li C, Tan X, Yan Y. HsamiRNA-31 regulates epithelial cell barrier function by inhibiting TNFSF15 expression Cell Mol Biol (Noisy-le-grand) 2016; 62 (4): 104-110.

13. Wang ZC, Lu H, Zhou Q, Yu SM, Mao YL, Zhang HJ, Zhang PC, Yan WJ. MiR-451 inhibits synovial fibroblasts proliferation and inflammatory cytokines secretion in rheumatoid arthritis through mediating p38MAPK signaling pathway Int J Clin Exp Pathol 2015; 8 (11): 14562-14567.

14. Sharma AR, Sharma G, Lee SS, Chakraborty C. miRNA-Regulated key components of cytokine signaling pathways and inflammation in rheumatoid arthritis Med Res Rev 2016; 36 (3): 425-439. 


\section{5-360}

15. Liu Y, Zhang XL, Li XF, Tang YC, Zhao X. miR-212-3p reduced proliferation, and promoted apoptosis of fibroblast-like synoviocytes via down-regulating SOX5 in rheumatoid arthritis Eur Rev Med Pharmacol Sci 2018; 22 (2): 461-471.

16. Fattah SA, Ghattas MH, Saleh SM, Abo-EImatty DM. Pre-micro RNA-499 Gene Polymorphism rs3746444 T/C is Associated with Susceptibility to Rheumatoid Arthritis in Egyptian Population Indian J Clin Biochem 2018; 33 (1): 96-101.

17. Jones SW, Watkins G, Le Good N, Roberts S, Murphy CL, Brockbank SM, Needham MR, Read SJ, Newham P. The identification of differentially expressed microRNA in osteoarthritic tissue and modulate the production of TNF-alpha and MMP13 Osteoarthritis Cartilage 2009; 17 (4): 464-472.

18. Hu SL, Chang AC, Huang CC, Tsai CH, Lin CC, Tang CH. Myostatin Promotes Interleukin-1 $\beta$ Expression in Rheumatoid Arthritis Synovial Fibroblasts through Inhibition of miR-21-5p Front Immunol 2017; 8: 1747.

19. Sun X, Wei J, Tang Y, Wang B, Zhang Y, Shi L, Guo J, Hu F, Li X. Leptin-induced migration and angiogenesis in rheumatoid arthritis is mediated by reactive oxygen species FEBS Open Bio 2017; 7 (12): 1899-1908.
20. Yoshida K, Nakai A, Kaneshiro K, Hashimoto N, Suzuki K, Uchida K, Hashimoto T, Kawasaki Y, Tateishi K, Nakagawa N, Shibanuma N, Sakai Y, Hashiramoto A. TNF- $\alpha$ induces expression of the circadian clock gene Bmal1 via dual calcium-dependent pathways in rheumatoid synovial cells Biochem Biophys Res Commun 2018; 495 (2): 1675-1680.

21. Gupta S, Su H, Agrawal S, Gollapudi S. Molecular changes associated with increased TNF- $\alpha$-induced apoptotis in naïve (TN) and central memory (TCM) CD8+ T cells in aged humans Immun Ageing 2018; 15 : 2. doi: 10.1186/s12979-017-0109-0. eCollection 2018.

22. Zhao G, Hu M, Li C, Lee J, Yuan K, Zhu G, Che C. Osteopontin contributes to effective neutrophils recruitment, IL-1 $\beta$ production, and apoptosis in Aspergillus fumigatus keratitis Immunol Cell Biol 2018. doi: 10.1111/imcb.12010. (Epub ahead of print)

23. Yan JE, Yuan W, Lou X, Zhu T. Streptozotoein-induced diabetic hyperalgesia in rats is associated with upregulation of Toll-like receptor 4 expression Neurosci Lett 2012; 526 (1): 54-58.

Received February 12, 2018. Accepted March 2, 2018. 